\title{
Effective management of pension scheme mergers
}

Received: 12th December, 2001

\section{Ian Greenstreet}

is a partner in the London office of the pensions unit at Hammond Suddards Edge, an international law firm. He regularly advises employers and trustees on all aspects of pension law including many pension scheme mergers. lan is a past contributor to Sweet \& Maxwell's Law of Pension Schemes and Pensions the New Regime: A guide to the Pensions Act 1995 and its regulations. Ian is also the author of Stakeholder Pensions - A Special Report published by Sweet \& Maxwell 2001.

\begin{abstract}
This paper considers, from the perspective of employers, how to project manage effectively the merger of pension schemes; discusses the legal constraints employers and trustees work under in relation to mergers; considers how to identify and to avoid potential problems before they happen; considers how to formulate the merger proposals; identifies the documentation required; discusses how to plan the communication process and deals with the transfer of assets and post merger formalities. It also looks at some technical issues relating to obtaining GN16 and section 67 certificates from Actuaries.
\end{abstract}

Keywords: mergers; GN16; section 67; section 37; stamp duty; transfers without consent; preservation; surplus

\section{Introduction}

Pension Scheme mergers can be very frustrating for employers. Multiple advisers create potential for significant fee growth. The legal issues are complex - employers will have to get to grips with GN16 certificates $^{1}$ and section 67 certificates $^{2}$ which sometimes the transferring scheme actuary will not give without changes to the merger proposals. Even worse, trustees will not do what they are told and start demanding benefit improvements as a condition of the merger.

Many problems with pension scheme mergers arise because of a lack of

Ian Greenstreet Hammond Suddards Edge, 7 Devonshire Square, Cutlers Gardens, London EC2M 4YH, UK.

Tel: +44 (0)20 7655 1000; Fax: +44 (0)20 7655 1001; www.hammondsuddards edge.com understanding of the legal constraints that the trustees are working under. If an employer understands what is going on, many of the problems associated with a merger can be avoided or overcome more effectively. A pension scheme merger, like any other complicated project, is capable of being managed effectively. It is important to appreciate, however, that it is the employer who should be driving the process. It is when the trustees or advisers drive the process that things start going wrong. Flow charts showing the key steps involved in pension scheme mergers are shown in Appendix 1.

\section{Back to basics - what is a merger and why might an employer want to merge schemes?}

Legally the word 'merger' is misleading. Schemes do not become one legal entity when they merge but the assets of one scheme (the 'Transferring Scheme') are transferred to the trustees of the other scheme (the 'Receiving Scheme'). In return, the Receiving Scheme trustees agree to take over the Transferring 
Scheme trustees' liability to provide benefits for the Transferring Scheme's former members. Usually the transfer of some or all of the members will be made without consent.

Employers may want to merge pension schemes for a number of reasons. They may want to harmonise benefits following an acquisition of a company with its own pension scheme or they may just want to save professional, investment management and administrative costs by merging two schemes.

Employers should never forget the objective of the merger eg, harmonisation of benefits and/or cost savings. If the cost in terms of benefit improvements that the Transferring Trustees are seeking as part of the merger discussions is too high the employer should not proceed with the merger. It should look at other options to achieve its objectives.

\section{The legal constraints}

The legal constraints under which trustees and sponsoring companies operate need to be understood. The key powers in the Transferring Scheme and the Receiving Scheme will be divided between the sponsoring employer and the trustees under the applicable trust deed and rules. Often the powers will be jointly exercisable and it is very rare for an employer to have the power to effect a merger without trustee consent.

Trustees and employers are subject to different duties in relation to the exercise of powers. Trustees hold all their powers and discretions in a 'fiduciary' capacity. This means that trustees must exercise any powers and discretions in the interests of the present and future beneficiaries of the scheme.

Under general trust law trustees must also exercise any powers in good faith and in a way that promotes the purposes of the scheme. They must also take advice where appropriate and take into account all relevant factors when making a decision and not be influenced by irrelevant considerations, otherwise there is a risk that the decision may be subsequently attacked. Where there are a number of different classes of beneficiaries such as pensioners, deferred members and active members, trustees must give proper consideration to the interests of the different classes of beneficiaries when exercising their powers. The duty to give property consideration to the interests of all classes of beneficiaries does not necessarily mean that the beneficiaries should be treated equally. Trustees can in certain circumstances prefer one class over another, but they should properly consider the interests of all classes. Case law suggests that they can also have regard to the impact that any course of action which they may take will have on the financial ability of the employer to make the contributions to the schemes. ${ }^{3}$

Employers do not generally hold any powers in a fiduciary capacity (ie, they can have regard to their own interests). However, it has been established that employers owe members of pension schemes an implied duty of good faith in relation to pensions. This means that they must not act in such a way that will break down the relationship of trust and confidence that exists between the members and the employer. An employer could not, for example, threaten that, unless the trustees agree to a merger, the employer would refuse in future to agree to any discretionary increases in the scheme. Employers therefore need to be careful in any negotiations with the trustees not to overstep the line and put undue pressure onto the trustees into agreeing to a merger (ie, the 'agree or else' approach). Using a carrot to persuade the trustees to 
agree to the merger is likely to be far more effective than a stick.

An employer needs to come up with a set of merger proposals that, on balance, the Transferring Trustees are likely to consider are more in the interests of the different categories of members than the alternatives. Even if the employer's proposals prefer particular classes of beneficiaries over others, it does not follow that the trustees will reject them (see below).

\section{Avoid creating conflicts before the negotiations even start}

The key people on an organisation with an interest in and the power to make decisions on pension issues are often also trustees. Typically the finance director and human resources director will be on the trustees board of the Receiving Scheme. Many of the trustees of the Receiving Scheme will also be members of the Receiving Scheme.

Ideally the company's proposals should be formulated by a company working group with no members who are also trustees. This avoids any potential for conflicts of interest arising. However, it is appreciated that this is not always possible. As long as the trustees who are also officers of the company are aware of the potential for conflicts and take appropriate professional advice, conflicts can be managed.

Under general trust law trustees should not put themselves in a position where their own interests or their duties to their employer conflict with the interests of the beneficiaries. However, most trust deeds provide that any decision of trustees will not be invalidated because a trustee also owes competing duties to his employer or is personally interested in the exercise of the power. Under statute there is no breach of trust merely because it gives rise to a conflict between his personal interest and his duties to the beneficiaries. ${ }^{4}$

Care needs to be taken to ensure that any requirements of company law ${ }^{5}$ and requirements of the memorandum and articles of association of the employing company are complied with in relation to the declaration of conflicts of interest.

\section{Are all these advisers really necessary?}

It is in the interests of the company that all parties are separately advised as it reduces the risk that the merger will be attacked subsequently. It also helps any conflicts to be managed more effectively. Ideally the sponsoring company, the Receiving Scheme trustees and the Transferring Scheme trustees should all have separate legal and actuarial advice. Trustees cannot rely on the skill and judgment of anyone appointed as legal adviser in relation to the Scheme other than by the trustees. ${ }^{6}$

Instructing three sets of lawyers and actuaries is going to be expensive. It is generally going to be necessary for the Transferring Scheme trustees to be independently advised by solicitors who are also not acting for the sponsoring company of the Receiving Scheme. To save costs, sometimes it may be possible for the Receiving Scheme's solicitors and actuaries to act for both the Receiving Scheme trustees and the sponsoring company without a conflict arising. Solicitors are subject to very strict conflict rules and should tell you whether, given the circumstances of the merger, this is likely to be possible. Quite often the Receiving Scheme trustees and the sponsoring employer will have a common interest in achieving a merger which results in the Transferring Trustee spending the minimum amount of any surplus on benefit improvements. Actuaries have less strict conflict rules but will still have to manage any conflict if they are acting for 
both the Receiving Scheme trustees and the company.

The best way to keep professional costs under control is to manage the merger process effectively and bring the extra sets of advisers into the process at the appropriate time.

\section{Preliminary due diligence}

The sponsoring employer should not finalise any merger proposals until it has carried out some preliminary due diligence. Due diligence should include:

- an analysis of the balance of powers in the two schemes eg, can a merger be achieved without trustee consent; what powers do the sponsoring employer and the trustees have if the merger does not proceed (ie, what is the alternative to a merger) and will the rules need to be amended to merge the schemes?

- obtaining up-to-date information on the funding position of the Transferring Scheme and the Receiving Scheme

- obtaining preliminary advice from its accountants on the accounting implications of the merger under both UK and any applicable international accounting standards

- obtaining preliminary input from the sponsoring company's solicitors about how to formulate the proposals in a way that avoids any major legal difficulties

- examining fund management agreements to see what notice period has to be given if any of the Transferring Scheme managers investment mandates are to be terminated as part of the merger

- examining the contractual terms of other advisers as the wind-up of the Transferring Scheme will terminate their appointment
- examining any insurance policies (eg additional voluntary contribution policies) held by the Transferring Scheme to establish if there are any penalties if they were to be discontinued.

\section{Funding due diligence in more detail}

The relative funding position of the Transferring Scheme and the Receiving Scheme will be a key factor in any merger negotiations. The sponsoring employers and also the trustees of both schemes will need to update actuarial assessment of the relative funding position of the two schemes. A similar basis should facilitate negotiations.

The ideal situation for a merger (from an employer perspective) is for the Receiving Scheme to be well funded and to be better funded or funded at the same level as Transferring Scheme.

If the Transferring Scheme is better funded than the Receiving Scheme there is likely to be pressure from the Transferring Scheme trustees, once they have taken advice, for benefit improvements. The relative size of the two schemes is also important when assessing the dilutive effect on any funding shortfall in the Transferring Scheme will have on the funding position in the Receiving Scheme.

If the Transferring Scheme is not solvent under the Minimum Funding Requirement the wind-up of the Transferring Scheme as part of the merger arrangements may give rise to a debt on the employer. ${ }^{7}$ If the scheme is 'being wound-up' a valuation has to be carried out by the scheme actuary. If the valuation reveals that the Transferring Scheme is not solvent on a similar basis to the minimum funding requirement, the employer will have to make a contribution to make up any shortfall. 
However, it may be possible to structure the merger as a two-stage process so that the assets and liabilities are transferred out before any wind-up commences. In this case, arguably no statutory debt should arise as when the Scheme is wound up there will be no assets and liabilities and no debt. However, care must also be taken to ensure that all the participating employers cease to participate at the same time otherwise a statutory debt may still arise. This is a difficult area and legal advice should be taken.

If a statutory debt arises the sponsoring employer and other employers participating in the Transferring Scheme may have to make an immediate payment to restore the scheme to 100 per cent funding on the MFR basis. If the Transferring Scheme had continued the employers may have had several years to make up the shortfall under the MFR requirements. This cash flow disadvantage may kill the merger negotiations before they have even started.

The Receiving Scheme trustees may be concerned about the dilution of the funding level and/or the 'flooding' of the scheme with new members enabling an employer to run off surplus more quickly by way of contribution holiday.

\section{Accounting due diligence in more detail}

The merger of pension schemes can have accounting implications both under UK and, where applicable, international accounting standards. If benefit improvements are granted these may have to be recognised immediately in the profit and loss account. There could also be an impact on the ongoing pension cost going forward. It is important that accountancy/actuarial advice is obtained early on in the merger proposals to ensure that there are no nasty surprises from an accounting perspective which may make the employer unwilling to proceed with the merger.

\section{Formulating the proposals}

The sponsoring company needs to formulate its merger proposals with its benefit consultants. In particular:

- Benefit Structure: The new benefit structure that will apply to the Transferring and Receiving Scheme members post merger needs to be settled. How will any differences from the existing benefit structures be dealt with? Will the active transferring employees be brought into the Receiving Scheme on standard terms with a past service credit, or will the existing structures continue to run in parallel? If harmonised benefits are to be granted and there are discretionary increases for pre-April 1997 service in the Transferring Scheme and guaranteed increases in the Receiving Scheme, how will this be dealt with? What about differences in final pensionable salary definitions? Will existing additional voluntary contribution options continue to be available in the Transferring Scheme post merger? There are lots of issues to think about.

- Benefit Improvements/Utilisation of Surplus: Consideration needs to be given to how any surplus will be utilised to achieve any harmonisation of benefits required. Will benefit improvements, be on offer to sweeten the deal and, if so, to whom? Will the sponsoring employer be able to access surplus by way of continued contribution holiday or otherwise post merger? Legally if trustee agreement to the merger is required there is likely to be pressure from the Transferring Trustees for benefit improvements, particularly if the Transferring Scheme 
is better funded. In the Courage case ${ }^{8}$ where the employer was seeking to access surplus and this required the trustees' agreement it was said that:

'Where the employer seeks repayment, the trustees or committee can be expected to press for generous treatment of employees and pensioners ...'

However, in a later Court of Appeal decision of Edge ${ }^{9}$ in different circumstances the Court did not consider the trustees to have acted wrongly by only making such recommendations as they felt to be fair to everyone involved in the fund (which did not include benefit improvements for pensioners and deferred pensioners although the trustees had regard to the fact that the pensioners had benefited from past increases). In this case, where the Court considered that the trustees were in a much weaker bargaining position than in the Courage case, the Court considered that the trustees were entitled to take the view that:

'... half a loaf was better than no bread.'

Nevertheless, it will be brave trustees who do not seek improvements where the Transferring Scheme has a significant surplus and is better funded than the Receiving Scheme.

- Indemnities: What indemnities, if any, will be offered to the Transferring Scheme trustees and the Receiving Scheme as part of the merger. Will any special protective provisions be offered to the Transferring Trustees to persuade them to agree to the merger.

The proposals, once formulated, need to be set out in a paper that can be put to the Receiving Scheme and Transferring Scheme Trustees.

\section{Understanding the trustees' position}

In formulating any merger proposals the sponsoring employer should have regard to the trustees' likely concerns. The Transferring Trustees are likely to have regard to the following factors when deciding what is the best available option for their members:

- The benefits that will be provided going forward for the active members - if the benefits are not as good as under the existing scheme this will be an issue (it is generally not in the interests of scheme members to agree to a cut in their benefits!).

- The relative security of members' benefits following the merger ie, what will the funding position of the merged scheme be like as compared with the funding position at the moment?

- The balance of power in the Receiving Scheme as compared with the Transferring Scheme ie, does the sponsoring employer have greater or less control in the Receiving Scheme than under the Transferring Scheme? Will the sponsoring employer have greater access to surplus, whether by way of contribution holiday or repayment of surplus, under the Receiving Scheme as compared with the Transferring Scheme?

- What benefit improvements (if any) are on offer as part of the merger out of any surplus available? Will benefit improvements be available just for the active members or for other categories of members as well? Trustees have a duty to give proper consideration to the interests of all categories of members - however, just because benefit improvements are not available for all categories does not mean that the trustees should turn down the proposals (see above). 
- Whether it is more or less likely that any discretionary practices with regard to pension increases or other benefits will continue in the Receiving Scheme (this will be an issue in relation to the granting of a GN16 certificate - (see below).

- What protection in terms of indemnities will the Transferring Trustees have following the merger?

- What is the likely alternative to the merger? Is it the continuation of the Transferring Scheme on its existing terms or is there a genuine possibility that the Transferring Scheme may be wound up? If a wind-up is possible are there sufficient assets to secure the members' benefits in full? Currently the cost of securing deferred members' benefits by purchasing annuities is so high benefits may have to be scaled down on a wind-up while a scheme may be more than adequately funded on an ongoing basis. In which case the merger of the scheme may be a better option even if no benefit improvements are on offer. If a wind-up of the scheme is possible will the Transferring Scheme trustees have power to continue the scheme as a closed scheme and, if so, is this a sensible option?

The Receiving Scheme trustees are likely to have regard to the following factors when deciding to agree to any merger:

- whether the merger can properly be regarded as promoting the purposes of the Receiving Scheme

- the effect any merger is likely to have on the security of members benefits under the Receiving Scheme. Are sufficient assets being transferred to fund the liabilities being taken over and is the merger going to have a dilutative effect on the Receiving Scheme's funding position?

- will the increased membership of the Receiving Scheme following the merger enable the employers to run off any surplus more quickly?

- the effect that any merger may have on the possibility of any discretionary practises continuing in the Receiving Scheme in the future

- any proposed benefit changes and/or improvements on offer for existing members if the merger goes ahead

- what indemnities or other obligations the Receiving Scheme trustees are being asked to enter into in any merger documentation.

\section{Other issues that need to be addressed before the proposals are put to the trustees}

\section{Planning of the communication exercise}

Planning of the communication exercise should start even before the proposals are put to the Receiving Scheme and Transferring Scheme trustees. Pensions can sometimes become a very emotive issue and need to be handled carefully.

Consideration should be given to whether outside communication consultants are to be instructed.

\section{Transfers without consent}

Will this be possible? Preliminary comfort should be sought that it will be possible to transfer all categories of members without consent. Broadly, a transfer without consent will only be possible if the Transferring Scheme actuary can sign a GN16 certificate. This will depend on the benefits to be provided and the relative funding of the two schemes (see Appendix 2). If transfers without consent are not possible it may be necessary to buy out the benefits of those members who cannot be transferred without 
consent. This may be expensive. Under the contracting-out requirements the member's consent is always required to a transfer of protected rights.

\section{Will any proposed amendments to the rules be possible?}

Any proposed modifications to the Transferring or Receiving Scheme rules needed to give effect to the merger may require a section 67 certificate from the applicable scheme actuary confirming the entitlements and accrued rights of the members acquired before the date of the rule modification will not be adversely affected. A section $37^{10}$ certificate may also be required for contracting-out purposes. Please see Appendix 2 for a detailed discussion of when section 67 and 37 certificates can be granted.

\section{Contractual issues}

Any major changes to pension benefits of active members could have contractual implications. Generally it is not possible to change employees' contracts of employment, including any pension terms, without obtaining individual consents. However, most contracts will say very little about pensions. All they will say typically is that:

'The employer operates the XYZ Pension Scheme. If eligible, employees will be able to join the XYZ Pension Scheme on its terms as set out in the rules including the power of amendment and discontinuance.'

It is, therefore, arguable that employees do not have a contractual right to a given level of benefits but only a right to be a member of the pension scheme on its terms from time to time. If the contractual right to amend or discontinue the scheme has been reserved (either expressly or implied) generally the employees will have no contractual right of redress if the scheme benefits are amended. However, even where the employer has an express contractual right to discontinue the scheme if, without good commercial reasons, it just discontinued the existing pension arrangements, it is arguable that there would have been an actionable breach of the implied contractual duty of good faith that employers owe to scheme members in relation to pensions.

\section{Preparation of draft merger documentation}

To have sensible discussions with the Transferring Scheme trustees draft merger documentation should be prepared by the sponsoring company's solicitors for inclusion in the pack to send to the trustees. The main legal documents that will be required to give effect to the merger are as follows:

- Amending Deed: If the existing powers are not wide enough to give effect to the merger proposals, it may be necessary to amend the rules of the Transferring Scheme and Receiving Scheme. A section 67 certificate may also be required from the actuary (see Appendix 2).

- Merger Agreement: A merger agreement should be entered into between the sponsoring companies and Trustees of both the Transferring Scheme and Receiving Scheme setting out the merger terms including:

- the benefits to be provided for the transferring members

- placing an obligation on the Transferring Scheme Trustees to transfer the assets of the Transferring Scheme to the Receiving Scheme

- placing an obligation on the Transferring Scheme Trustees to 
take over responsibility to pay

benefits and administrative

expenses from a certain date, otherwise reserves will have to be retained by the Transferring Scheme trustees

- contain any indemnities/discharges from the Receiving Scheme trustees to the Transferring Trustees and from the sponsoring employer of the Receiving Scheme to the Transferring and Receiving Scheme trustees - contain an obligation from the Receiving Scheme trustees to comply with the data protection principles under the Data Protection Act 1998 in relation to any data transferred.

- Amending Deed: Modifications may need to be made to the rules of the Receiving Scheme to set out the benefits to be provided. If the modifications might affect any accrued rights or entitlements acquired before the date of modification a section 67 certificate will be required.

- Deed of Participation: If all the employers with employees in the Transferring Scheme are not currently participating in both the Transferring and Receiving Scheme it will be necessary to prepare a deed admitting them to participation in the Receiving Scheme and obtain Revenue Approval to such participation.

- Deed of Transfer/Assignment: It is necessary to prepare documentation legally transferring the assets of the Transferring Scheme to the Receiving Scheme.

\section{Putting the merger proposals to the Transferring and Receiving Scheme trustees}

The key to successful control of the merger process is to bring the
Transferring and Receiving Scheme trustees and their advisers into the process at the correct time. It is much easier for the trustees, from a trust perspective, to respond to a clearly formulated set of proposals. The Transferring Scheme trustees can then consider whether the proposals are on balance in the interests of the members compared with the alternatives. The Receiving Scheme trustees can then consider whether the merger proposal furthers the purposes of the Receiving Scheme and is not detrimental to existing members.

The Transferring Scheme trustees should be sent a pack consisting of:

- a paper setting out the merger proposals

- draft merger documentation prepared by the sponsoring company's solicitors

- a benefit comparison between the Receiving Scheme and the Transferring Scheme can be included if one has already been prepared. This will avoid some duplication of effort although the Transferring Trustees' advisers will need to check it

- a balance of power comparison and comparison of the winding-up provisions in the Receiving Scheme and the Transferring Scheme can also be included if one has been prepared. This will avoid duplication of effort although the Transferring Scheme trustees will want to check it.

The trustees will then seek their own legal and actuarial advice on the proposals. A meeting between the trustees the company and their respective sets of advisers can then be arranged at which the trustees can raise any concerns they have about the proposals.

There is a very fine balance to be struck in any negotiations. Any proposals 
should be structured in a way that the trustees could properly conclude that they are in the interests of the members and then put firmly to the trustees. However, the sponsoring employer must recognise that the trustees' advisers have a job to do and if they feel they are being asked to rubber-stamp proposals it is likely to antagonise them. The trustees and their advisers will want to add something to the process.

They may in any event have legitimate concerns. For example, sometimes if the Transferring Scheme has a significant surplus the Transferring Scheme trustees may be concerned to ensure that if the Receiving Scheme was wound up shortly after the merger, their former members are not disadvantaged. Sometimes this issue is addressed by giving the former members priority under the Receiving Scheme wind-up rule to the extent that the Receiving Scheme still holds surplus attributable to the assets transferred. Provisions of this type are hard to operate and the sponsoring employer should resist permanently altering the wind-up rule. Altering it for a limited period may be just about workable. In any event, the new statutory wind-up priority order under the Pensions Act 1995 cannot be overridden. ${ }^{11}$

Once any outstanding issues have been resolved the merger documentation needs to be finalised by the sponsoring company's and the trustees' solicitors.

\section{Implementation and communication process}

Once the merger proposals have been agreed in principle, Revenue consent will need to be obtained to the proposed merger. A form PS 295 needs to be lodged in relation to the proposed bulk transfer to the Receiving Scheme before it takes place. ${ }^{12}$
The announcements and any elections (for the active members) relating to the merger will need to be issued to the active members, deferred members and pensioners together with the relevant contracting-out notices. Meetings will need to be arranged with the active members to explain the new benefit structure. The working of the existing authority to deduct employee contributions should be checked. If it is not wide enough to cover contributions to the Receiving Scheme, a new authority to deduct will need to be obtained. New death-in-service benefit nomination forms will generally need to be signed by the members unless the merger documentation expressly provides that the Receiving Scheme Trustees can have regard to the nomination forms sent to the Transferring Scheme trustees.

The contracting-out notices will vary depending on the basis on which the schemes are contracted-out. However, assuming both schemes are contracted-out under the statutory reference test and the sponsoring companies hold group contracting-out certificates:

- a notice of intention to surrender the existing group contracting-out certificate held by the sponsoring employer of the Transferring Scheme will need to be issued

- a notice of intention to vary the group contracting-out certificate held by the sponsoring employer of the Receiving Scheme to add any new participating employers will need to be issued. ${ }^{13}$

The notices of intention have to be sent or delivered to:

- active employees in respect of whose employment the election is made

- the trustees and scheme administrator of the scheme to which the election relates 
- where the scheme holds insurance policies to secure benefits, any insurance company, and — any recognised trade unions. ${ }^{14}$

Where there are recognised trade unions the notices must be issued three months before the proposed date of the election unless the trade unions agree in advance and in writing to a shorter period when the period can be reduced to one month. ${ }^{15}$ If there are no recognised trade unions, only one months' notice needs to be given. These notice periods need to be built into the project management timetable. The employers are required under the legislation to consult with any recognised trade unions about the proposed contracting-out changes.

Under the preservation requirements where there is to be a transfer of a member's accrued rights without consent, information about the proposed transfer and details of the value of the rights to be transferred (including rights in respect of death in service benefits and survivors' benefits) have to be furnished to the member not less than one month before the proposed transfer takes place. ${ }^{16}$ Again this time limit needs to be built into any project management timetable.

\section{Finalisation of merger documentation}

Once any relevant time limits for the issue of notices have expired:

- the GN16 certificate needs to be obtained from the Transferring Scheme actuary

- any section 67 PSA and section 37 rule amendment certificates need to be obtained.

Meetings of the sponsoring companies and the Transferring Scheme and
Receiving Scheme trustees to formally approve the final versions of the documentation and to authorise the execution of the documents.

\section{Transfer of assets}

Following the:

- approval and signing of the merger documentation

- approval of the transfer by the Pension Schemes Office, and

- expiry of any relevant time limits for contracting-out and preservation purposes,

there will still be various legal formalities to transfer the Transferring Scheme's assets to the Receiving Scheme. These formalities vary depending on the type of assets to be transferred. If the Transferring Scheme holds insurance policies (eg, additional voluntary contribution policies) or annuity policies in the names of trustees these need to be formally assigned to the Receiving Scheme trustees. Notices of assignment will also need to be sent to the policy providers.

Any shares or securities are likely to be held by the custodian on behalf of the Transferring Scheme trustees under the CREST system as nominees for the Transferring Trustees. Transfer is likely to take place electronically using the CREST system. There is a special 'flag' (Transaction Stamp Status 5) which should be used under CREST relating to pension scheme mergers. The use of the 'Flag' should be accompanied by a 'letter of direction' in a similar form to the example given in the relevant guidance issued by CREST. If the letter of direction is stamped $\&^{5}$ there should be no ad valorem stamp duty reserve tax liability on a transfer. The assumption of the liabilities by the Receiving Scheme trustees is not 
regarded as stampable consideration. However, since February 2000 there may be a problem with transfers of certain types of unit trusts on pension scheme mergers. Unit trusts are specifically exempt from stamp duty, so it is no longer possible to avoid any stamp duty reserve tax by stamping the letter of direction $\ell^{5}$ to 'frank' the liability for stamp duty reserve tax. This issue has been raised with the Stamp Office ${ }^{17}$ who have confirmed that it is possible for the unit trust managers to redeem the units on a pro rata in specie basis immediately prior to the transfer of the assets.

However, this is not much help where a pension scheme has a small unit holding in a unit trust where the unit trust manager may only be prepared to pay the scheme its cash entitlement. The redeemed stock then cannot be reinvested in another unit trust without a stamp duty cost. In view of the current uncertainty on this issue it is advisable to approach the stamp office for confirmation that SDRT is not payable in relation to the transfer of UK units trusts.

If there are any direct holdings of freehold property they will also need to be legally transferred to the Receiving Scheme Trustees by entering into the appropriate conveyance or transfer (in the case of registered land). Any cash can be physically transferred to the Receiving Scheme trustees bank account.

\section{Post merger formalities - receiving scheme}

\section{Member nominated trustee/director requirements}

The bulk transfer of the Transferring

Scheme members to the Receiving

Scheme will be a 'relevant event' for the purposes of the member nominated trustee/director requirements. ${ }^{18}$ If the Receiving Scheme trustees consider that, as a result of the merger, it would be detrimental to the interests of the Receiving Scheme members for the approval of any alternative arrangements or appropriate rules for the selection of trustees under the member nominated trustee requirements to continue to have effect, they can give notice to that effect to the employers. The employers then have one month to decide whether they wish to propose alternative arrangements to the statutory requirements for the appointment of one third member nominated trustees/directors.

\section{Admission of new employers - Revenue formalities}

If new employers need to be admitted to participation in the Receiving Scheme a copy of the completed deed of participation and a form PS274 needs to be lodged with the Revenue to obtain its approval to the admission of these companies. ${ }^{19}$ This must be done within 180 days of the end of the Receiving Scheme year in which the companies are admitted.

\section{Variation of contracting-out certificate}

After the expiry of the relevant notice period an election will need to be made to vary the existing contracting-out certificate held in respect of the Receiving Scheme to include any new participating employers.

\section{Post merger formalities - transferring scheme}

There are various other post merger formalities that should not be overlooked:

- Earmarking Information: Where an earmarking order has been made against the trustees of the Transferring Scheme they must give the Receiving 
Scheme trustees a notice containing certain prescribed information about the earmarking order within (broadly) three months of the date the transferring member acquires rights under the Receiving Scheme and in any event within 21 days of the date the Transferring Scheme assets are transferred to the Receiving Scheme. ${ }^{20}$

- Transfer of Administrative Records: Arrangements need to be made for the transfer of administrative records from the Transferring Scheme to the Receiving Scheme trustees.

- Section 75 Valuation: The wind-up of the Transferring Scheme may trigger a requirement to carry out a valuation for the purposes of section 75 Pensions Act 1995 (see above).

- Surrender of Transferring Scheme Contracting-out Certificate: An election to surrender the Transferring Scheme contracting-out certificate will have to be filed with the COE Group Elections Section of the NI Contributions Office of the Inland Revenue.

- Section 50 Approval: The Secretary of State has to approve formally any arrangements for securing or transferring of contracted-out rights where the Transferring Scheme is wound up. ${ }^{21}$ Such approval will normally require a reconciliation of the scheme's records with those of the contracted-out employment group of the Inland Revenue NI Contributions Office. The relevant procedures are explained in the Cessation of Contracted-out Pension Schemes manual (CA15). The process is supposed to be completed within two years of the cessation of contracted-out status although the Secretary of State does have discretion to extend the period. ${ }^{22}$ However, we have been involved in cases where the reconciliation process has taken three or four years to complete.

- Audited Accounts: Wind-up accounts should be prepared by the Scheme auditors.

- Revenue Formalities: When the wind-up of the Transferring Scheme is completed the Revenue should be notified of its discontinuance on Form PS 199. ${ }^{23}$

- Pensions Registry: The Pensions Registry should be notified of the completion of the wind-up on form PR12. The final year's Pension Registry return needs to be filed and the fee also needs to be paid if the wind-up of the scheme is completed part way through the year.

\section{Appendix 1}

\section{Merger: principal steps}

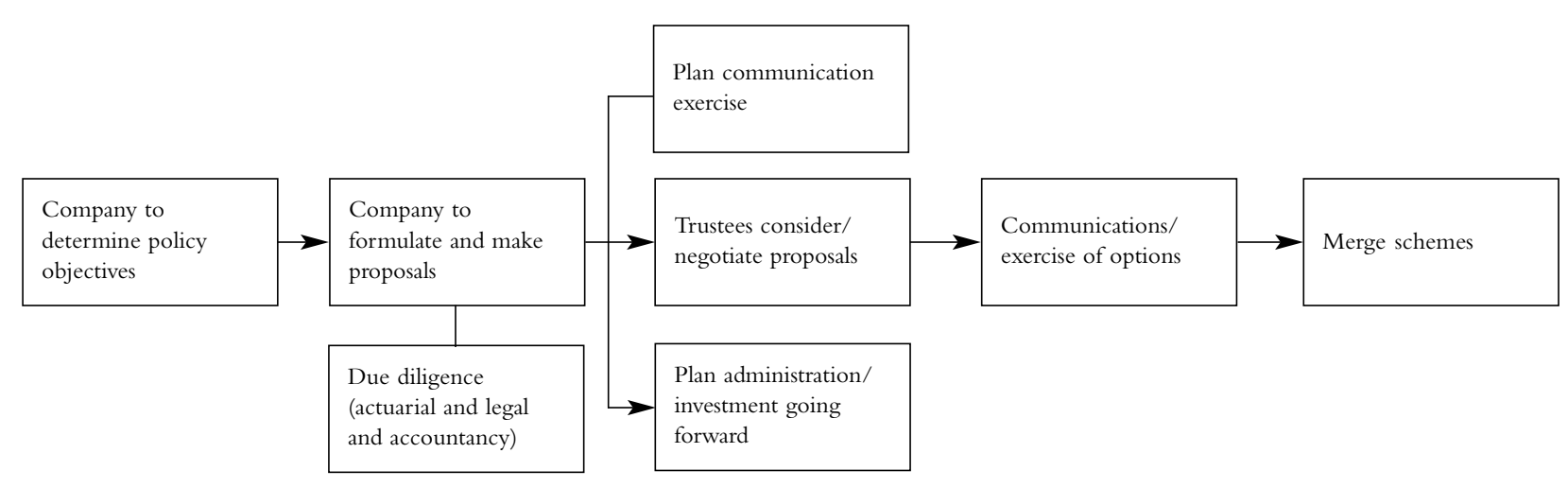


Pension scheme merger: detailed legal procedures - two defined benefit schemes

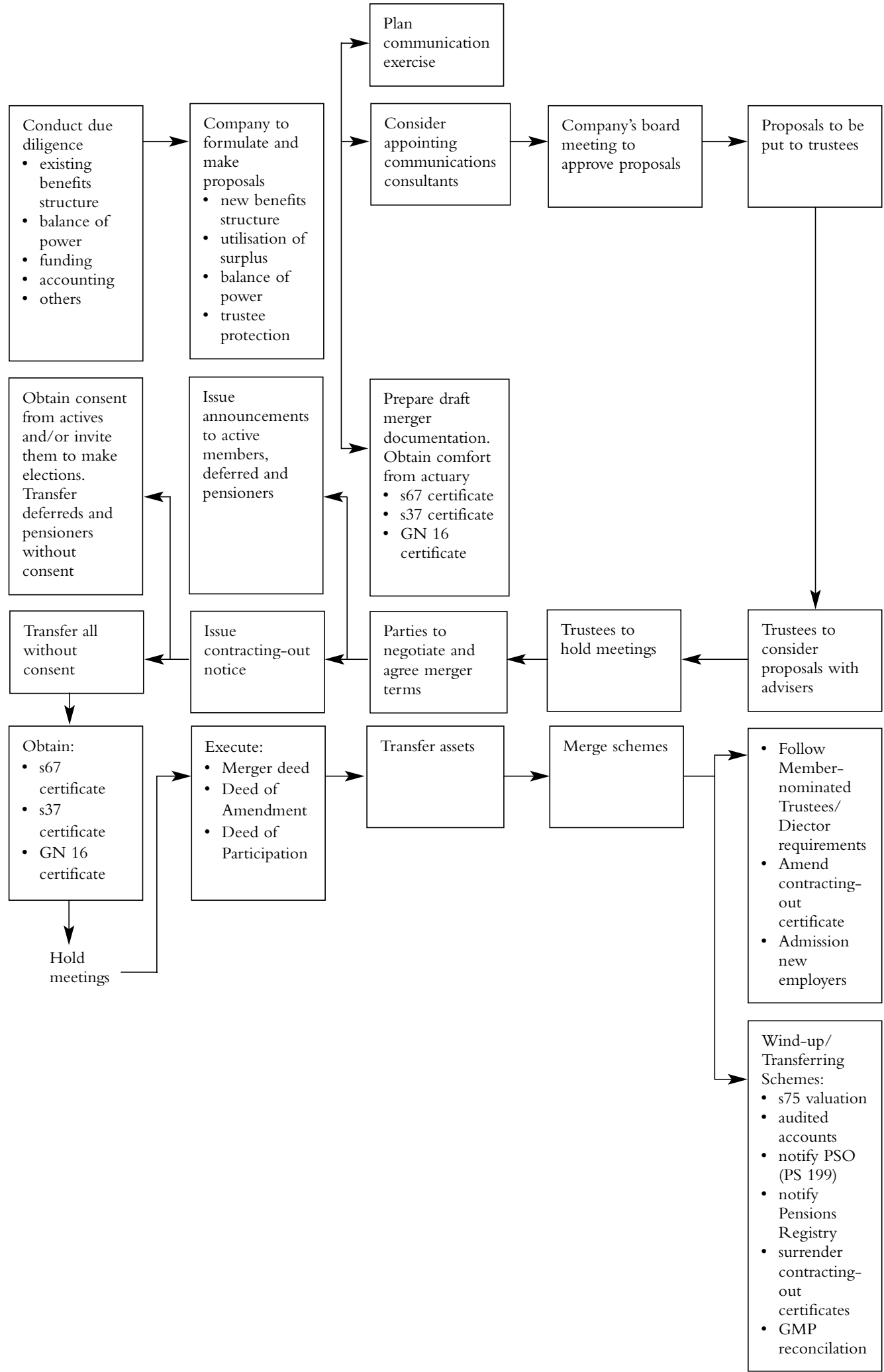




\section{Appendix 2: Some technical points}

\section{Transfers without consent - GN16 certificates}

In practice it may not be possible to merge two schemes if the consent of the pensioners and deferred members has to be obtained. Transfers without member consent can only be made where authorised by the Transferring Scheme rules. Also they can only be made in certain prescribed circumstances under the preservation requirements ${ }^{24}$ which include obtaining a GN16 Certificate from the Transferring Scheme actuary. If a GN16 certificate cannot be obtained it may be necessary to buy-out the benefits of the non-consenting members which may be expensive.

Under the preservation requirements ${ }^{25}$ a transfer can only be made without consent if the rights of a member are being transferred from the Transferring Scheme to the Receiving Scheme and either:

- the Transferring Scheme and the Receiving Scheme apply to employment with the same employer; or

— the Transferring Scheme and the Receiving Scheme apply to employment with different employers, the member concerned is one of a group in respect of whom transfers are being made from the Transferring Scheme to the Receiving Scheme, and either:

- the transfer is a consequence of a financial transaction between the employers; or

- the employers are (connected employers).

It has been suggested in the past that above requirement will prevent a transfer without consent of the benefits of deferred members who have never been in the pensionable employment of an employer participating in the Transferring Scheme. However, in the Merchant $\mathrm{Navy}^{26}$ case the Court was prepared to give Regulation 12(2) a broad rather than a narrow interpretation to enable transfers of short service benefits to be effected without the need to obtain the relevant member's consent provided always that there is some kind of employment connection between the Transferring Scheme and the Receiving Scheme. So transfers without consent can be made provided both the Transferring Scheme and the Receiving Scheme will apply to employment with the same employer, whether or not the transferring beneficiary is or has every been employed by that employer. However, there may still be problems merging a closed scheme with another scheme where no active members are being transferred.

Under the preservation requirements, for a transfer to be made without consent it is also necessary for the Transferring Scheme actuary to certify that:

- the Transfer credits to be acquired for each member under the Receiving Scheme are, broadly, no less favourable than the rights to be transferred

- where it is the established custom for discretionary benefits or increases in benefits to be awarded under the Transferring Scheme, there is good cause to believe that the award of discretionary benefits or increases in benefits under the Receiving Scheme will (making allowance for any amount by which transfer credits under the Receiving Scheme are more favourable than the rights to be transferred) be, broadly, no less favourable. 
In giving the certificate the Transferring Scheme actuary must, as a matter of professional conduct, comply with actuarial guidance note GN16 (Retirement Benefit Schemes - Bulk Transfers). GN16 currently imposes additional and slightly different requirements to those contained in the Occupational Pension Schemes (Preservation of Benefit) Regulations 1991. The Government has indicated that it will sort this discrepancy but has still not done this. This is not helpful.

Under GN16:

- before giving the certificate the actuary needs to be satisfied that for and in respect of each member:

- the value of the transfer credits to be granted in the Receiving Scheme is not less favourable than the value of the member's past service rights in the Transferring Scheme, and

- the value of any discretionary benefits or increases in benefits to be granted in the Receiving Scheme is not less than the value of any discretionary benefits or increases in benefits in the Transferring Scheme. In this regard the actuary should make allowance for any amount by which the value of the transfer credits under the receiving scheme is greater than the value of the rights to be transferred.

- The actuary is required to draw to the attention of the Transferring Trustees the effects of any differences in the winding-up rules of the two schemes, including the priority rules and the disposal of surplus.

- The actuary should only give the certificate if he is satisfied that the benefits of the transferring members in the event of a winding-up of the Receiving Scheme immediately following the transfer would not be materially less than those payable in the event of the winding-up of the Transferring Scheme immediately before the transfer.

- The benefits in the Receiving Scheme do not need to mirror those of the Transferring Scheme for the actuary to give the certificate.

However, the actuary will need to be satisfied that no member, beneficiary or contingent beneficiary is to be given materially inferior benefits.

Under GN16 the Transferring Scheme actuary:

- Need not consider, in giving the certificate, the pension terms and conditions for future service benefits under the receiving scheme compared with those that would have existed under the transferring scheme.

- Needs to take into account the financial strengths of the Transferring and Receiving Schemes but only to the extent that the financial strengths affect the rights and any discretionary benefits or increases in benefits of the Transferring Members. The actuary should make it known to the Transferring Scheme Trustees that he has taken no account of the financial strengths of the principal and participating employers in giving the certificates.

GN16 can cause problems or even prevent a merger taking place. For example:

- It is highly unlikely that an actuary will ever give a GN16 certificate in relation to a transfer from a defined benefit scheme to a defined contribution scheme, or vice versa, as it would represent a major change in the nature of the rights of members. 
- If the Transferring Scheme is better funded than the Receiving Scheme, and following the merger, the Receiving Scheme does not have sufficient assets to secure fully all benefits by purchasing annuities, the benefits which could be provided if the Receiving Scheme was wound up immediately after the transfer may be materially less than the benefits that would have been secured if the Transferring Scheme had been wound up immediately before the transfer.

- As a consequence of the requirement to provide transfer credits that are equivalent in value and the requirement that non members are to be given materially inferior benefits, the benefits to be granted under the Receiving Scheme for pensioner and deferred members are going to have to be virtually identical to the existing benefits.

- Sometimes employers will want to offer the active membership of a scheme on a markedly different benefit structure on the basis that, if they do not consent, they will be granted the same benefits as they would have received under the Transferring Scheme as early leavers. This is not possible under the preservation requirements as they will not receive a credit of equivalent value in the Receiving Scheme. ${ }^{27}$ Under the preservation requirements account has to be taken of projected future salary increases when valuing any credit. However, there may be ways round this problem if the merger is structured carefully so that the active members cease to be in pensionable service before the merger takes place.

- Where there is the established custom of the Transferring Scheme to grant discretionary benefits or an award of increases to benefits the actuary has to be satisfied that the practice will continue unless there is some other compensating increase to benefits. However, this problem can often be addressed as under GN16 the actuary can take account when giving a certificate of a declaration of intent made jointly by the Receiving Scheme administrator and employer to pay such discretionary benefits or increases subject to the availability of funds.

If the Transferring Scheme members are contracted-out of the State Scheme on a protected rights basis it will only be possible to make a transfer with member consent. This has caused particular problems for proposed scheme mergers of defined benefit schemes where a scheme, which had previously been contracted-out of the State Scheme by providing guaranteed minimum pensions, opted to be contracted-out on a protected rights basis for post April 1997 pensionable service. There are similar problems in relation to the transfer of 'safeguarded rights' where a scheme offers an internal benefit option on pension sharing on divorce to a former spouse. There can also be problems relating to transfer of guaranteed minimum pensions and section $9(2 \mathrm{~B})$ rights without consent where formerly contracted-out schemes are involved.

\section{Section 67 Certificates - extracting one may be difficult}

As well as extracting a GN16 certificate from the Transferring Scheme actuary, it may also be necessary to obtain section 67 certificates from the Transferring and Receiving Scheme actuaries before any amendments can be made to the rules. For example, either or both of the Transferring Scheme and the Receiving Scheme rules may need to be amended 
to insert powers permitting the merger or the rules of the Receiving Scheme may need to be amended to document the benefits offered to the members transferred from the Transferring Scheme.

Section 37 Pension Schemes Act 1993 certificates may also be required if amendments are made. Section 37 certificates confirm that a scheme contracted-out by virtue of meeting the statutory reference test will continue to do so post amendment.

Broadly under section 67 of the Pension Act 1995 no modification can be made to a scheme which would or might affect any entitlement, or accrued right, of any member of the scheme acquired before the power is exercise unless either the consent requirements or the certification requirements are met and where the power of amendment is not vested in the trustees, the trustees have approved the amendment. ${ }^{28}$

Under the certification requirements, broadly the actuary has to certify to the trustees that in his opinion the exercise of the power in the proposed manner would not adversely affect any member of the scheme (without his consent) in respect of his entitlement, or accrued rights, acquired before the power is exercise. $^{29}$

Where there is no power in the rules of the Transferring Scheme to make a transfer, there has been some doubt in the past whether legally such a power can be inserted without a section 67 certificate being first obtained. There was also doubt whether an actuary could properly give such a certificate in relation to a general rule amendment (as opposed to one permitting a merger on particular terms) as the requirements of GN16 are not as stringent as those of section 67 Pensions Act 1995.

The Occupational Pension Scheme (Modification of Schemes) Regulations 1996 have now been amended to make it clear that section 67 does not apply to the insertion of a scheme rule to permit the transfer of benefits without consent where such a transfer is expressed to be conditional upon compliance with regulation 12 of the Occupational Pension Schemes (Preservation of Benefit) Regulations 1991 (transfer of benefits without consent). However, arguably this relaxation only applies to the transfer without consent of the benefits of deferred members entitled to a short service benefit under the preservation requirements, not to pensioners' benefits that have come into payment on retiring from service. A section 67 certificate will still be required in relation to the insertion of a rule permitting a transfer of pensioners' benefits. The Merchant Navy provides judicial authority that it would be open to the Scheme Actuary to give a section 67 certificate if he is satisfied that the merger proposals would not adversely affect any member of the Scheme in respect of his entitlement. ${ }^{30}$

Before entering into a deed setting out the benefits to be provided for in the Receiving Scheme it may be necessary to obtain a section 67 certificate. If the deed is entered into before the merger takes place it might be argued that it could not possibly affect any entitlements or accrued rights and a section 67 certificate is not required. However, if the view is taken that, when deciding whether entitlements or accrued rights are adversely affected, the actuary should look at the security of the existing members' benefits a section 67 certificate is required. Lawyers' views on this issue differ. Interestingly while the joint option of Nicholas Warren QC and Paul Newman obtained by the Institute of Actuaries on section 67 considered that there were good arguments that security did not have to be taken into account it did not rule it out. 
Where the Transferring and the Receiving Scheme are contracted-out under the statutory reference test it will also be necessary to obtain a certificate under section 37 of the Pension Scheme Act 1993 confirming that none of the alterations to be made by an amending deed will prevent the Receiving Scheme continuing to meet the statutory reference test.

\section{(C)Ian Greenstreet}

\section{References}

1 Actuarial Guidance Note: GN16 Retirement Benefit Schemes - Bulk Transfers — Published by the Institute and Faculty of Actuaries.

2 Section 67 Pensions Act 1995.

3 Edge v Pensions Ombudsman [1999] PLR 215.

4 Section 39 Pensions Act 1995.

5 Section 317 Companies Act 1985.

6 Section 47(3)(a) Pensions Act 1995.

7 Section 75 Pensions Act 1995.

8 Re Courage Group's Pension Plan Scheme [1987] 1 WLR 495.

9 Edge v Pensions Ombudsman [1999] PLR 215.

10 Section 37 Pensions Act 1995.

11 Section 73 Pensions Act 1995 as modified by The Occupational Pension Schemes (Winding-up) Regulations 1996 SI 1996/3126.

12 Occupational Pension Schemes Practice Notes on Approval of Occupational Pension Scheme IR12 (2001) PN10.36.

13 Occupational Pension Schemes (Contracting-out) Regulations 1996 SI 1996/1172, Regulation 12.

14 Occupational Pension Schemes (Contracting-out) Regulations 1996 SI 1996/1172, Regulation 3.
15 Occupational Pension Schemes (Contracting-out) Regulations 1996 SI 1996/1172, Regulation 5.

16 Occupational Pensions Schemes (Preservation of Benefit) Regulations 1991 - SI 1991/167, Regulation 12(4B).

17 Exchange of correspondence between Association of Pension Lawyers and Stamp Office between April 2000 and August 2000.

18 The Occupational Pension Scheme (Member Nominated Trustee and Directors) Regulations 1996 SI 1996/1216, Regulation 20(2)(a).

19 Occupational Pension Schemes Practice Notes On Approval of Occupational Pension Schemes IR 12 (2001), PN 21.5.

20 The Pension Sharing on Divorce Regulations 2000 SI 2000/1123, Regulation 4(5).

21 Pensions Schemes Act 1993, section 50.

22 The Occupational Pension Schemes (Contracting-out) Regulations 1996 SI 1996/2172, Regulation 45.

23 Occupational Pension Schemes Practice Notes on Approval of Occupational Pension Schemes IR 12 (2001), PN 14.3.

24 Occupational Pension Schemes (Preservation of Benefit) Regulations 1991, SI 1991/167, Regulation 12.

25 Occupational Pensions Schemes (Preservation of Benefit) Regulations 1991, SI 1991/167, Regulation $12(2)$.

26 Merchant Navy Ratings Pension Fund Trustees Limited $v$ Chambers and Others [2001] 29 PBLR (26).

27 Occupational Pensions Schemes (Preservation of Benefit) Regulations 1991, SI 1991/167, Regulation 12(4).

28 Section 67(3)(b) Pensions Act 1995.

29 Section 67(3)(a)(i) and 67(4)(a) Pensions Act 1995 and The Occupational Pension Schemes (Modification of Schemes) Regulations SI 1996/2517, Regulation 3(1).

30 Merchant Navy Ratings Pension Fund Trustees Limited $v$ Chambers [2001] 29 PBLR (26) 22 . 